\title{
Integration of Electric Vehícles in the Electric Utility Systems
}

\author{
Cristina Camus, Jorge Esteves and Tiago Farias \\ Instituto Superior de Engenharia de Lisboa, Instituto Superior Técnico \\ Portugal
}

\section{Introduction}

In the last decades, the energy use for electricity production and for the transportation sector have more than duplicated (IEA - WEO, 2007) and today face a number of challenges related to reliability, security and environmental sustainability. The scientific evidence on climate change (IPCC, 2007) has been calling for urgent cross-sector emission cutting and electrified transportation is in the portfolio of the technology options that may help to solve the problem (IEA - ETP, 2008). In most of OCDE countries the transportation and electric power systems contribute to the majority of $\mathrm{CO}_{2}$ emissions (IEA - WEO, 2008) and most of the fossil fuels (coal, natural gas and oil) used to produce electricity and for transportation are, in many of these countries, imported. Oil accounts to the majority of this primary energy imports and more than $60 \%$ of it, is used for transportation (mainly road transportation) and so is responsible for the majority of emissions associated to the transport sector. All these facts are pressing decision makers/manufacturers to act on the road transportation sector, introducing more efficient vehicles on the market and diversifying the energy sources.

The technological evolution of the Electric Drive Vehicles (EDV) of different types: Hybrid Vehicles (HEV), Battery Electric Vehicles (BEV) and Fuel Cell Vehicles (FCV), will lead to a progressive penetration of EDV's in the transportation sector taking the place of Internal Combustion Engine Vehicles (ICEV). The next step in EDV technological development, already announced by some of the main automakers, (EV World, 2009) is the possibility of plugging into a standard electric power outlet so that they can charge batteries with electric energy from the grid. A lot of companies including many key and niche players worldwide are reported to have been developing models for the coming years in the segments of battery powered electric vehicles, Plug-In Hybrid Electric Vehicles (PHEVs), and fuel cell electric vehicles (EV ReportLinker, 2007).

By shifting currently non-electric loads to the grid, electric vehicles might play a crucial role in the integration of these two critical elements of the whole energy system: power generation and transportation. In a scenario where a commitment is made to reduce emissions from power generation, the build-up of new intermittent power capacity is problematic for the electric systems operation (Skea, J, et al., 2008) and usually needs large investments in energy storage. The addition of extra load from electric vehicles in the electricity system can be challenging, if together both systems are more efficient and able to reduce overall emissions.

Furthermore, for future energy systems, with a high electrification of transportation, Vehicle to Grid (V2G) concepts can offer a potential storage capacity and use stored energy in 
batteries to support the grid in periods of shortage. By itself, each vehicle is small in its impact on the power system, but a large number of vehicles could have a significant impact either as an additional charge or a source of distributed generating capacity (Kempton and Tomic, 2005a; Kempton and Tomic, 2005b).

This chapter is concerned with studying the potential impacts of the electric vehicles on the electricity systems, with a focus on the additional power demand, power generation emissions associated with EVs and the role of demand side management (DSM) strategies in supporting their penetration as well as the economic impacts of EVs on electric utilities.

The analysis of the impact on the electric utilities of large-scale adoption of plug-in electric vehicles from the perspective of electricity demand, $\mathrm{CO}_{2}$ and other green house gas emissions and energy costs can be studied for two different electric utility's environments: A big electric system synchronized with similar systems within the same Continent, and a small Island, a lower electric isolated system. Each case has very different characteristics the most important ones are the robustness of the systems, the isolated system needs more backup power installed and usually has less variety in the production technologies. Other major difference is that in a small Island, due to its dimension and apartness, there is no room to run an electricity market, so that the whole service of electricity supply is provided by a regulated monopoly. These differences have influence on the final electricity price formation.

Many studies regarding battery electric vehicles and Plug in hybrids are being performed in different countries. In the US, for instance, the capacity of the electric power infrastructure in different regions was studied for the supply of the additional load due to PHEV penetration (Kintner-Meyer et al., 2007) and the economic assessment of the impacts of PHEV adoption on vehicles owners and on electric utilities (Scott et al., 2007). Other studies (Hadley, 2006) considered the scenario of one million PHEVs added to a US sub-region and analyzed the potential changes in demand, impacts on generation adequacy, transmission and distribution and later the same analysis was extended to 13 US regions with the inclusion of GHG estimation for each of the seven scenarios performed for each region (Hadley, 2008). The ability to schedule both charging and very limited discharging of PHEVs could significantly increase power system utilization. The evaluation of the effects of optimal PHEV charging, under the assumption that utilities will indirectly or directly control when charging takes place, providing consumers with the absolute lowest cost of driving energy by using low-cost off-peak electricity, was also studied (Denholm and Short, 2006). This study was based on existing electricity demand and driving patterns, six geographic regions in the United States were evaluated and found that when PHEVs derive $40 \%$ of their miles from electricity, no new electric generation capacity was required under optimal dispatch rules for a 50\% PHEV penetration. A similar study was made also by NREL (National Renewable Energy Laboratory) but here the analysis focused only one specific region and four scenarios for charging were evaluated in terms of grid impact and also in terms of GHG emissions (Parks et al., 2007). The results showed that off-peak charging would be more efficient in terms of grid stress and energy costs and a significant reduction on $\mathrm{CO}_{2}$ emissions was expected thought an increase in $\mathrm{SO}_{2}$ emissions was also expected due to the off peak charging being composed of a large amount of coal generation. The results obtained in one place on earth cannot be used in other regions only the methodologies. Apart from reasons that are related to car use habits and roads' topology, there is the electricity production source mix that is different from place to place, more expensive in some places and with more use of renewable sources in others. These 
differences will also be focused on this chapter and the way they contribute to the EVs' fuel/energy costs and the emissions balance between the power generation and the road transportation sectors with electric mobility.

\section{Electric utility systems}

In this section, a description of the electric power systems demand is done emphasizing its evolution along a day and the contribution that electric vehicles may have for leveling the power consumption diagram. Examples of the typical load profiles filled with the different technologies available (renewable sources, big hydro and thermal units) are presented, as well as the possible percentage of renewable in the electricity production. Then, the emissions associated with the electric vehicles' recharging are accounted.

To study the economic impacts for the two case studies, the different rules for technology dispatch are described in a market environment and in the case of a traditional integrated electric system. In this section an explanation of how the price for end consumers (where electric cars are included) is formed will be done with examples taken from a market environment and from a vertically integrated company in an isolated Island.

\subsection{Electricity demand}

Nowadays, electric power systems are designed to respond to instantaneous consumer demand. One of the main features of power consumption is the difference in demand along the day hours, the week days and seasons. Fig. 1 shows, as an example, the hourly demand profiles of the Portuguese electric system. Each curve represents a week of worth data from four different seasons in 2008 and illustrates the variation in electricity demand. It can be observed that, in this country, the annual peak demand occurs during winter months (December or January), in the evening.

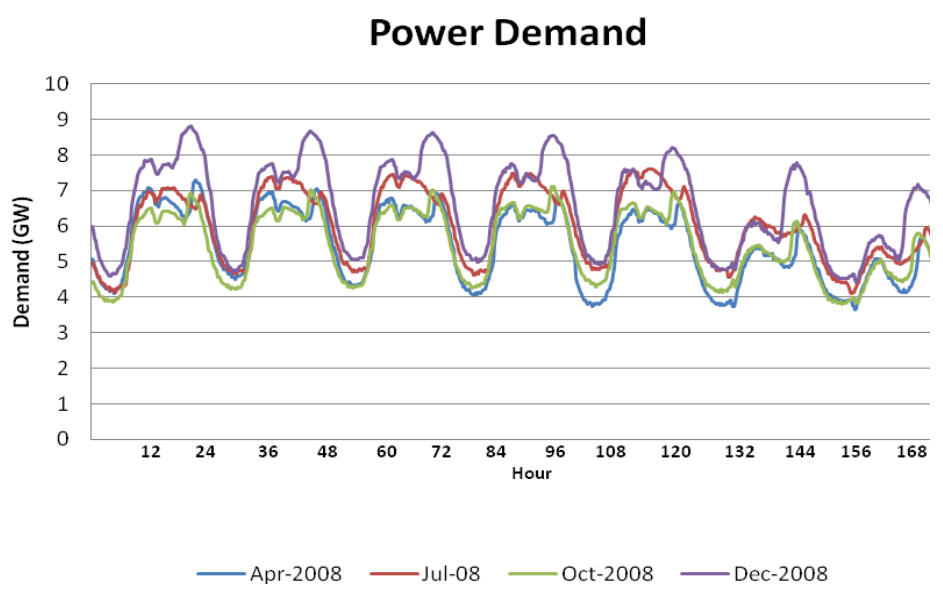

Fig. 1. Power demand profiles in Portugal for different seasons

This variation in daily and seasonal demand could mean that there is always some underutilized capacity that could be used during off peak hours. Looking at average values, 
Fig. 2 presents the evolution of the hourly average power consumption in Portugal over the 24 hours of the day during the whole year 2008. This evolution along the day has nevertheless a valley during the night that represents about $60 \%$ of the peak consumption and so has great financial consequences with the need of having several power plants that are useless and an underutilized network during the night. This situation gives the opportunity for electric vehicles contribution for levelling the power consumption diagram.

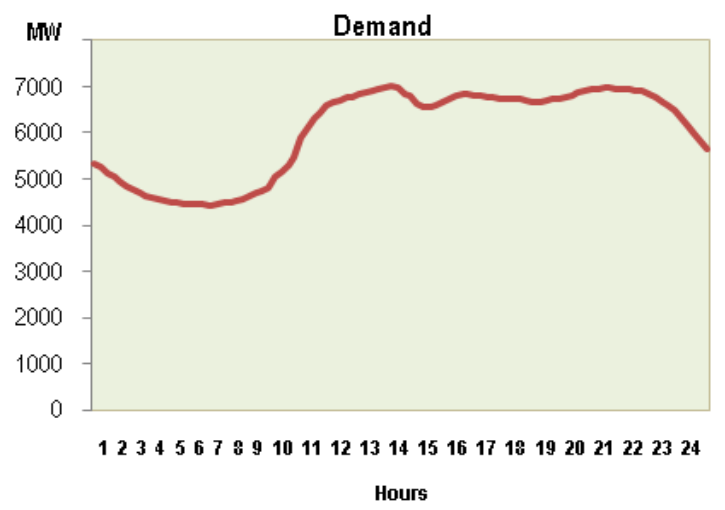

Fig. 2. Example hourly average power consumption during (weekdays in Portugal mainland year 2008)

As an example, Fig. 3 shows the estimated contribution for the power consumption diagram levelling when considering different levels of the electric vehicles penetration. Portugal mainland was used as an example and it was considered that $85 \%$ of the electric vehicle charging happens uniformly during the valley hours (from $11 \mathrm{pm}$ to $8 \mathrm{am}$ ) with the rest charge happening uniformly during the other 14 hours of the day. The extra energy that each electric vehicle should charge from the grid in average was considered about $2.5 \mathrm{MWh}$ per year, more or less $7 \mathrm{kWh}$ per day plus a $10 \%$ in transmission losses.

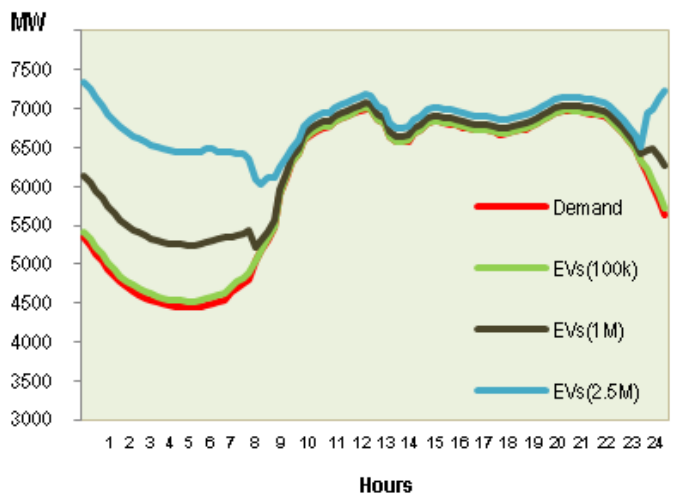

Fig. 3. Electric vehicles contribution to the consumption diagram leveling 
As can be observed in Fig. 3 only with a high penetration of vehicles like ca. 1million units (almost $1 / 4$ of the country's light duty fleet), the impacts are visible in the consumption profile. The main question is how to incentivise off-peak charging?

It is easy to foresee major congestion problems in already heavily loaded grids and voltage profile problems in predominantly radial networks, particularly if the peak load periods coincide with EV charging periods. Hence, if no load management strategies are defined, significant technical problems will occur and their drawbacks might even be larger than the economic/environmental benefits arising from electric vehicles usage (Fig.4).

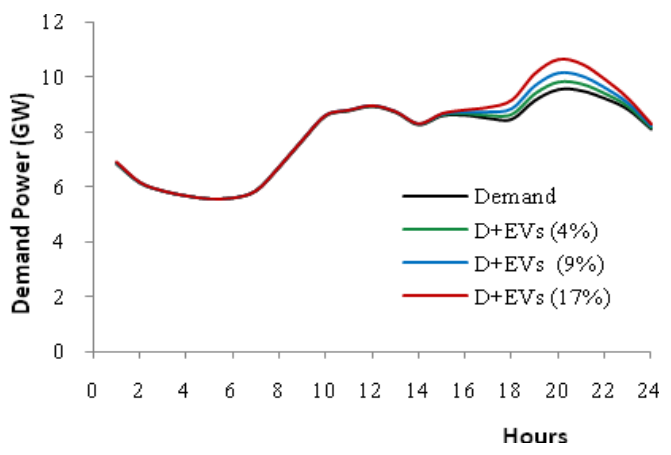

Fig. 4. Load profile simulation of the peak demand weak for year 2015 with 4, 9 and 17\% light duty fleet replacement with EV's that recharge at peak hours in Portugal mainland.

The management strategies to prevent peak recharge can be adopted in two ways:

a. By developing a dynamic price signal approach such that EV will charge predominantly during low energy price/demand moments or

b. By developing a technical management system such that charging can be distributed during valley hour periods and at times when there is large renewable power generation.

In a scenario of mass EVs penetration, the recharging profiles are important for the electric utility system's sake and their effects on peak consumption, electricity prices and grid congestion should be carefully foreseen and studied.

\subsection{Electric power consumption and power plants technologies}

The hourly average power consumption during a day presented in Fig. 2 has an equivalent diagram when analyzing the distribution during the 24 hours of the day of the annual energy consumed. Fig. 5 presents this distribution and also the different power technologies that generated this energy demand.

The great difference between the consumption at valley and at off-valley hours represents a barrier to the penetration of generation technologies that need to work more hours per year in order to became economically viable (usually with low unit variable costs but with large fixed costs) or non dispatchable units (renewable energies).

The effective use of the country's power plant fleet can be illustrated by the load duration curve (LDC), where the hourly average power over the whole year is sorted by decreasing order constituting a curve that begins with the year peak at hour 1 and the smallest demand at hour 8760 as illustrated in Fig. 6. In this example, the unutilized capacity could be 
annually 4000 GWh. Nowadays some of this capacity is used in pumping during off-peak hours. In 2008, about 700GWh were used for pumping to provide energy storage in reservoirs available for the peak hours. Without increasing capacity it would be possible to account with around $3000 \mathrm{GWh}$ a year for extra off-peak loads that could be used in plug-in electric vehicles' recharging. Considering a $3 \mathrm{MWh} /$ year of extra energy needed to charge an $\mathrm{EV}$, it is possible to have one million EVs charging their batteries during valley hours, without any more investments in power installed and transmission lines.

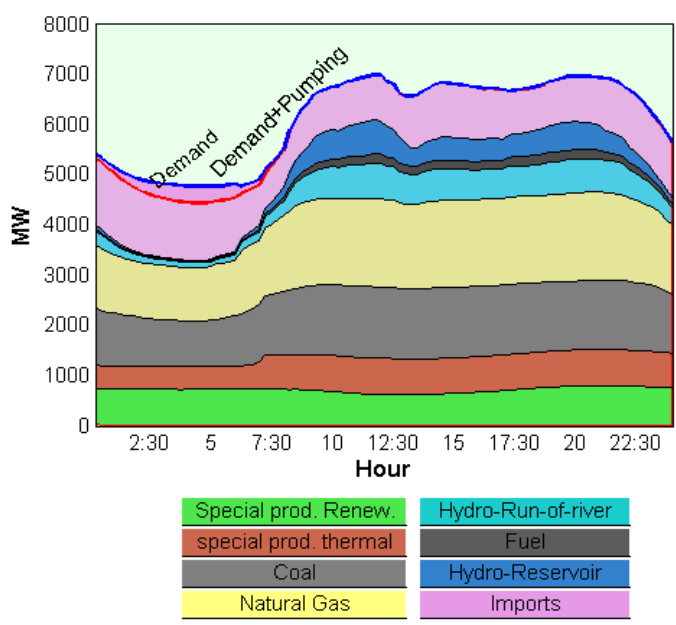

Fig. 5. Example of hourly energy consumption with used power plants technologies

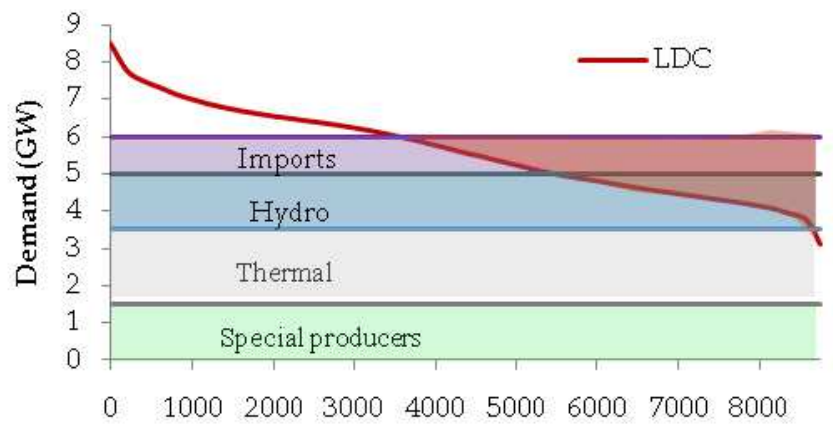

\section{Hours}

Fig. 6. Load duration curve for Portugal in year 2007

In addition to the fixed costs associated with underutilized capacity, the significant cycling that occurs on a daily basis creates additional costs for plants due to the constantly varying loads that could require generators to operate well below the "design point" of optimum efficiency. Power plant cycling also increases operation and maintenance requirements. 
This last situation is more visible for instance at St. Miguel Island in Azores, where the geothermal energy production (renewable energy without $\mathrm{CO}_{2}$ emissions that should be used as base load due to its impossibility of production variation) penetration is limited by the valley consumption. If base load electricity generation is much higher than actual demand, excess electricity will be wasted unless it is coupled to a storage system. This is an example, where the use of EVs, charged during off-peak hours, allow the development of a production technology from a renewable, endogenous source, with no $\mathrm{CO}_{2}$ emissions, against the systematic fuel imports (for vehicles and for electricity production).

S. Miguel has $27 \mathrm{MW}$ of existing geothermal capacity and the government wants to expand this capacity to meet future demand. Expanding existing capacity would mean that geothermal production will meet 40MW (EDA 2009). Current base load electricity demand is nowadays less than 40MW (Fig.7).

There is the possibility of increasing the geothermal capacity in 3MW by 2011 and $10 \mathrm{MW}$ in 2013 , but these investments are limited by the off-peak demand. Even considering a demand increase of $4 \%$ for years 2010 to 2013, there is not enough off-peak demand to fill the valley and at the same time assure at least a $10 \%$ of fuel power to prevent any shortage of the renewable energy sources.

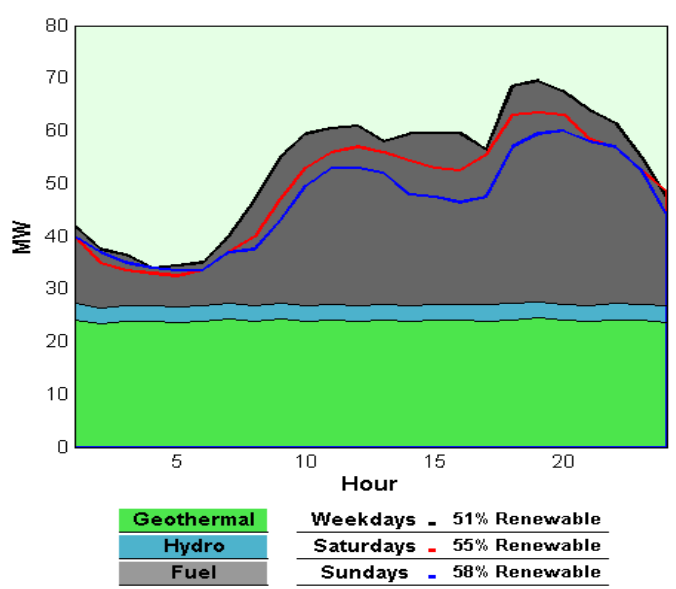

Fig. 7. Typical Winter Power consumption diagram at the S. Miguel Island, Azores, Portugal

As stated in last section, the fact that the valley demand, in this case, is about half the value of peak demand, gives the opportunity for electric vehicles contribution for levelling the power consumption diagram. The extra demand for charging the vehicles at each hour of the day is computed using equation 1 .

$$
P_{i}=\frac{E_{\text {Vavg }}\left(1+p_{\text {loss }}\right) p_{\text {ch } \arg e}}{h_{\text {ch } \arg e}} N
$$

Where $E_{\text {Vavg }}$ is the daily average energy needed for charging a vehicle, $p_{\text {loss }}$ is the percentage of energy lost in the transmission lines, $p_{\text {charge }}$ and $h_{\text {charge }}$ are respectively the percentage that is charged in each period (valley and off-valley) and the length of the considered period (in hours) and $\mathrm{N}$ the number of vehicles. 
Considering that $85 \%$ of the vehicles will uniformly recharge at night, the introduction of these vehicles will create and additional electricity demand that, in the context of today's electricity generation mix, will be fulfilled by the running fuel oil power plants (Fig. 8).

As expected, the percentage of renewable energy decreases and in terms of marginal emissions, they are simply being transferred from the tail pipes to the fuel power plants chimneys.

Considering an emissions rate of $830 \mathrm{gCO}_{2} / \mathrm{kWh}$ for the fuel power plants, the additional $\mathrm{CO}_{2}$ emissions to daily charge EVs (an extra energy of $86 \mathrm{MWh}$ ), should be 71.4 tons of $\mathrm{CO}_{2}$. The TTW daily emissions avoided if these same vehicles were conventional was about 120 tons.

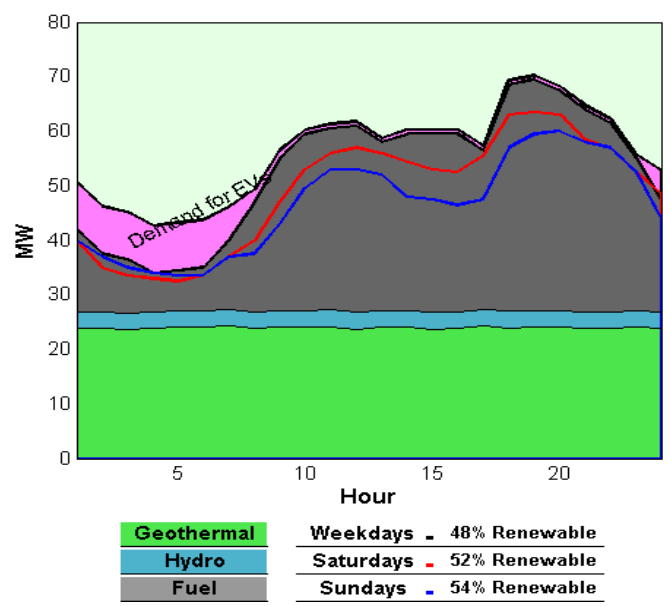

Fig. 8. Load profile in S. Miguel for Winter season with EVs extra demand (30\% of Light Duty fleet replaced for EVs)

However, if additional renewable electricity installed capacity is deployed, then the vehicles will also be running on renewable electricity. It can be considered that these EVs charged during off-peak hours are charged $100 \%$ with renewable energy. In fact there are three possible approaches:

1. It is considered the EVs as marginal load and as stated in Fig. 8, the energy and emissions associated with EVs charging would be mainly on fuel.

2. It is considered the EVs as a base load because they justify the increase in renewable base load generation and the energy and emissions associated with EVs are from renewable sources (zero emissions).

3. It is considered the EVs equal to the other load and the energy and emissions associated to EVs charging would be an average of the production mix. In this case the emissions associated with EVs recharging is as stated by equation 2

$$
\text { Emissions }_{\text {EV }}=\frac{\text { Demand }_{E V}}{\text { Demand }_{\text {TOTAL }}} \text { Emissions }_{\text {TOTAL }}
$$

These different approaches will lead to different $\mathrm{CO}_{2}$ emissions associated to EVs' recharge (in this example, $8 \%$ of total daily electricity consumption). 
In the first case, a daily 71.4 tons of $\mathrm{CO}_{2}$ emissions for EVs recharge under the considered scenario of EV penetration, in the second case, a daily zero emissions for EVs recharge and in the third case a 37 tons.

It is possible to see in Fig. 9, for instance for the typical Spring load profile that the new geothermal plus wind power penetration are not possible unless they increase valley consumption.
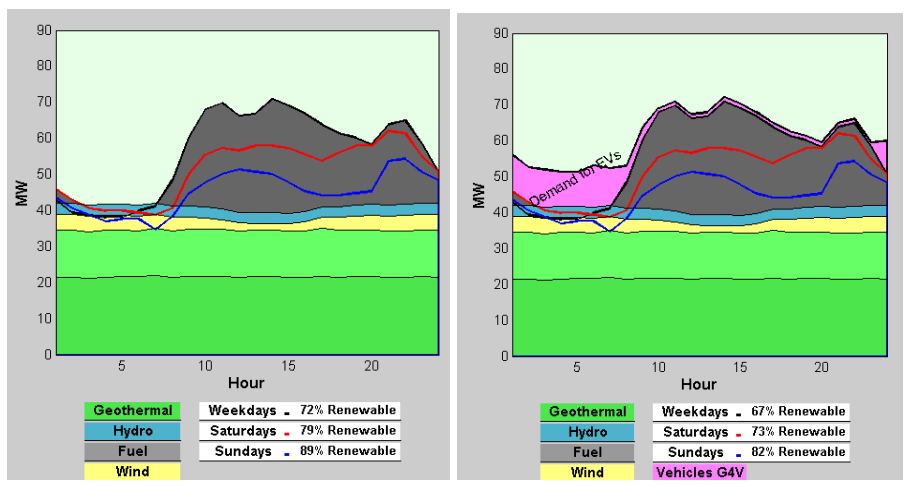

Fig. 9. Expected load profile in S. Miguel for Spring (2013), 4\% demand increase, $9 \mathrm{MW}$ of wind, 13MW of new geothermal power and 30\% LD fleet replacement by EVs.

The $\mathrm{CO}_{2}$ emissions factors, unit consumption and daily usage of vehicles considered in this analysis are resumed in Table 1.

\begin{tabular}{|c|c|r|r|r|r|r|}
\hline & \multicolumn{2}{|c|}{ CO2 Emissions } & \multicolumn{3}{c|}{ Unit Consumption } & Daily \\
\cline { 2 - 7 } & $\mathrm{kg} /$ litre & $\mathrm{kg} / \mathrm{kWh}$ & litres/100km & $\mathrm{kWh} / 100 \mathrm{~km}$ & $\mathrm{~kg} / \mathrm{kWh}$ & $\mathrm{km}$ \\
\hline ICEV Gasoline & 2.31 & & 7 & & & 32 \\
\hline ICEV Diesel & 2.68 & & 6 & & & 32 \\
\hline Fuel Plants & & 0.83 & & & 0.25 & \\
\hline EV & & & & 123 & & 32 \\
\hline
\end{tabular}

Table 1. Emission factors considered for the LD fleet and fuel power plants and average unit energy consumption.

It is easy to see that even considering that EVs are recharged by fuel, there are advantages in the $\mathrm{CO}_{2}$ emissions balance, as the daily 120 tons from the car tail pipes, are replaced by 72 tons in the fuel power plants chimneys. Although the correct mode is to attribute emissions for the percentage of electricity consumption to EVs' recharge, and that is only 37 tons.

\subsection{Electricity costs}

Electricity supply is considered a service of general economic interest. In the past, the electricity industry was organized as vertically integrated state-owned monopolies and consequently not subjected to the normal rules of competition. The liberalization process was put into force in many countries including in the European community (EC) in 1996 by Directive 96/92/EC, and led to the unbundling of activities. This directive defined common rules for the gradual liberalization of the electricity industry with the objective of 
establishing one common European market. Vertically integrated utilities have been vertically separated or unbundled and barriers to entry in generation and retailing were being removed to create competition.

In the two case studies presented in this chapter, two situations are analyzed: In the case of a small isolated system, a vertically integrated company is considered and the average unit production costs are used to define the merit order for technology dispatch. In the case of a continental European country, the marginal production costs are used to provide a supply curve and schedule the technology dispatch and find the wholesale price by market simulation.

\subsubsection{Average unit production costs and rules for technology dispatch}

The unit average cost for each technology is an average value that contains many simplifications. The cost functions are not linear and the average costs depend highly on the performance points in which the plants usually work. There are also the start-up costs (higher if there is a cold start) that should increase unit average cost if the plants don't work in a continuous state. In a monopoly context, the unit commitment service is centrally provided by the system operator as all the units belonged to the same company. In a market context this decisions are private and individual companies will predict the price of energy for the time under consideration and will then incur the cost of starting up if they expect to make a profit.

In this case, simple empirical rules are applied to distribute the energy source technologies to provide for the different scenarios of daily load profile. The rules used to order the power technologies that support expected demand plus EVs consider:

1. The special producers either renewable or thermal (special producers like cogeneration) are the first in order;

2. The cheaper technologies follow afterwards. For each case, the cheaper technologies enter in increasing cost order until a certain percentage of the power installed is used and only then follows the next technology;

3. Production from reservoirs are used only in peak hours;

In any case the technical limits of each group committed to electricity production should be taken into account. In this case the imposed limitation is made by the power installed in each technology.

In the S. Miguel (Azores) case study, as a volcanic Island, the renewable source is mainly geothermal. Geothermal power plants are characterized by high capital investments for exploration, drilling wells and plant installation but low cost for operation and maintenance, so that they should be considered base load plants.

The unit costs per technology, considered in this example are described in Table 2 and the unit average production cost depends on the electricity mix. In table 2 there are two examples of electricity production mix and the associated average production costs. It is easy to see that the use of more fuel power plants instead of geothermal ones makes the unit variable costs higher due to fuel cost. Fuel prices tend to increase because of world oil demand increase and it must also not be forgotten that, associated to fuel plants use, there are the $\mathrm{CO}_{2}$ emission costs that also tend to increase due to increasing environmental concerns.

It is also easy to see that the available technologies for electricity production make electricity costs expensive in S. Miguel Island. This has to be added to the fact that, an isolated system 
needs more redundancy and power installed in thermal plants to assure a high level of security of supply. This also increases fixed costs (the cost of power assurance).

\begin{tabular}{|l|c|c|c|}
\hline $\begin{array}{l}\text { Production } \\
\text { Technology }\end{array}$ & $\begin{array}{c}\text { Unit costs } \\
€ / \mathrm{MWh}\end{array}$ & $\begin{array}{c}\text { Production } \\
\text { scenario 1 }\end{array}$ & $\begin{array}{c}\text { Production } \\
\text { scenario 2 }\end{array}$ \\
\hline Geothermal & 33 & $37 \%$ & $51 \%$ \\
\hline Wind & 82 & $4 \%$ & $4 \%$ \\
\hline Hydro & 80 & $3 \%$ & $3 \%$ \\
\hline Fuel & 100 & $56 \%$ & $42 \%$ \\
\hline Average unit prod. cost $(€ / \mathrm{MWh})$ & 74 & 65 \\
\hline
\end{tabular}

Table 2. Unit average costs per technology, percentage of production scenarios and unit average production costs.

Added to the production costs there are also the costs associated to transmission lines use. Customers have to pay for the net's investments and maintenance and at the end for the service of distribution, accounting and billing. As all these services are supplied for the same vertically integrated company in a monopoly context, the final prices that end customers have to pay for electricity supply are regulated.

The impact EVs have on overall costs, depend on the additional variable cost associated with generating more electricity to serve the Plug-in vehicles' charging. Average variable costs may rise with increased electricity sales because higher cost generation plants are brought to service. Assuming though, no new infrastructure investment, average fixed costs will decrease, because the existing debt-service obligation is spread over more energy sold.

The time of vehicles charging is crucial for this analysis. An off-peak recharge can, in this example increase the penetration of geothermal power, decrease variable unit costs and fixed unit costs while at the same time reduces emissions and fuel oil consumption and imports.

\subsubsection{Marginal production costs and rules for technology dispatch}

To use the marginal production costs to schedule technologies to the expected load, a market simulation can be done with the demand and supply curves interception. A supply curve per technology should be generated. These curves should be added to generate a whole supply curve. Supply curves per technology are generated based on the expected power installed per technology and the supply curves verified in the past. As an example it can be observed the supply curves for the Portuguese units for the different technologies that play in the Iberian Electricity (MIBEL) spot market. In Fig.10 is an example of the supply curves per technology that occurred in two winter days, $(2009 / 01 / 12)$ at $12 \mathrm{~h}$ and $(2010 / 01 / 19)$ at $22 \mathrm{~h}$.

The supply curves in 2010 (the right hand side graphic in Fig. 10) show very low priced bids in hydro due to climate influence and also some low priced bids in natural gas due to more available supply (860MW were installed in the production system during the year 2009). 

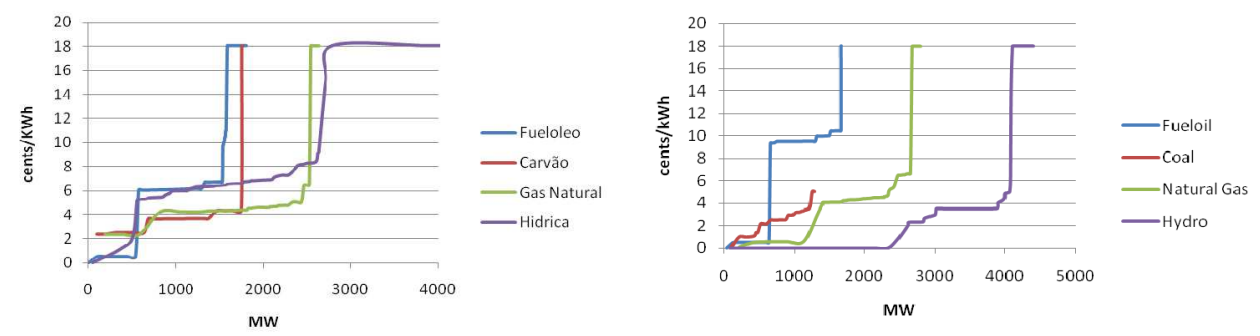

Fig. 10. Supply curves per technology for day 22 Jan 2009 at $12 \mathrm{~h}$ and 19 Jan 2010 at $22 \mathrm{~h}$ in the Portuguese market

The supply curves to be generated would represent different scenarios according to the expected power installed per technology, a dry or wet year scenario and the season. There are in the majority of the cases, 2 steps in the supply curves for each technology. The amplitude of the slops depends on the hydrologic conditions of the hydro resources and the natural gas availability. If there is too much of these resources, low priced platforms are expected at the beginning of the supply curves as observed for year 2010 in Fig. 10. The power where the steps occur and its amplitude depends on the power installed in the technology, the climate conditions scenarios, season and hour of the day. The rules for supply curves generation are the following:

1. There are four cases of supply curves per technology associated with each season (Spring, Summer, Autumn or Winter);

2. The expected power installed in each technology in the year in study is an input that limits power generation;

3. The scenarios to be studied (a dry year with high priced hydro resources or a wet year with low priced hydro and natural gas offers) are inputs that lead to different supply curves shape;

4. Two or three slops are generated for each technology with more or less the same shape of the past supply curves observed as seen in Fig. 10.

5. According to the scenario studied, the season and power installed, the slops of the supply curves are generated with the same shapes of past technology's supply curves observed in similar conditions. A small randomness that represents the observed variations is also programmed.

6. The supply curves generated for each technology are added in ascending order of price to form a global supply curve that will intersect demand.

An example of supply curves for year 2020 in Portugal mainland can be seen in Fig. 11.

In this case, the rules for technologies dispatch are:

1. The special producers either renewable or thermal (special producers like cogeneration) are the first in order;

2. The technologies with lower marginal costs follow afterwards. For each hour, according to demand level, the intersection gives market price and quantity per technology that will fulfill the daily load profile.

In this case, the wholesale electricity price is formed by supply and demand curves intersection. An increase in demand makes demand curve shift to the right and so electricity prices rise as the curves intersection occurs at a higher point in the slop. As an example, it is 
possible to see price formation for instance in hour 5, in the Portuguese sub-market, for the 23th Jan 2008 with the real data available at Market operator (OMEL 2009) site. It is possible to see the effects of an increase in off-peak load to plug-in vehicles recharging, in the market prices. As an example, considering that a huge amount of EVs were charging at this hour (5 a.m.) with an extra $800 \mathrm{~kW}$ power demand. The demand curve shifts to the right (Fig. 12). The price rises for almost three cents and some of the previous low cost clients (the pumping charges) were not supplied because they had lower priced buying bids.

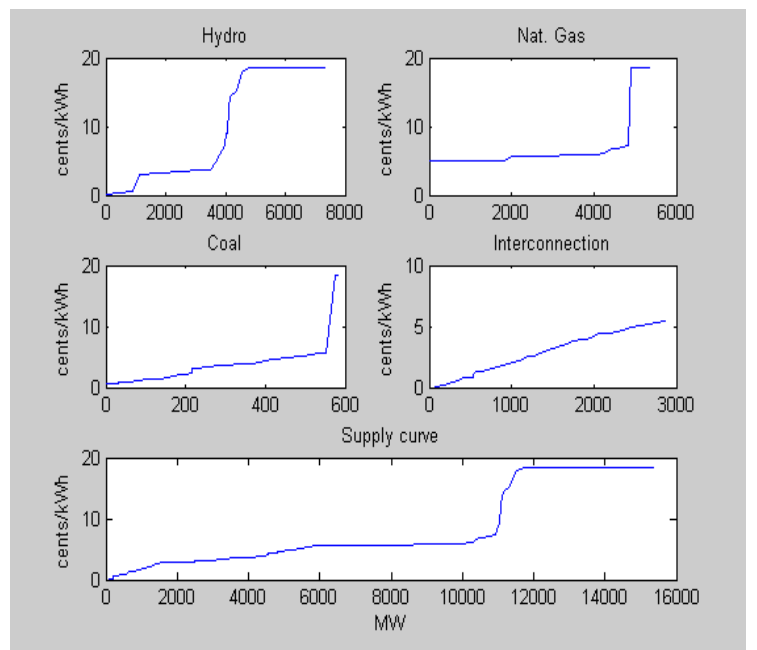

Fig. 11. Scenario of supply curves per technology for year 2020 in the Portuguese market
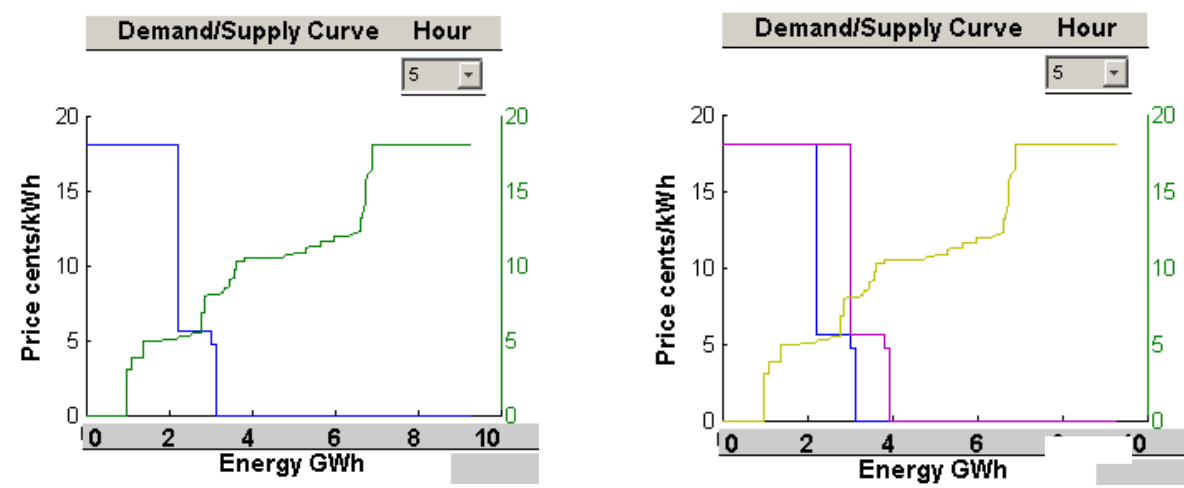

Fig. 12. Price formation in the Portuguese sub-market at hour 5 (economic simulation) and the effect of an extra $800 \mathrm{MW}$ of power for EV off peak recharge has in the market price.

The leveling of load profile may have the consequences of making the hydro-pumping less profitable. In fact, the reversible hydro plants' profits come from the discharging and selling at peak prices revenues less the costs from pumping with energy bought with off-peak prices. The following relation must occur: 


$$
\pi_{\text {peak }} E_{\text {peak }}>\pi_{\text {off-peak }} E_{\text {off-peak }} / \eta_{p}
$$

Where $\pi_{\text {peak }}, \pi_{\text {off-peak }}$ represent the peak and off-peak prices, $E_{\text {peak }}, E_{\text {off-peak }}$ the peak energy sold when discharging and the off-peak energy bought for pumping and $\eta_{p}$ the total performance of the hydro reversible system.

\subsubsection{Electricity costs for end consumers}

Over the wholesale prices, there come the net access prices. The national regulator establishes the access and pricing rules of the transmission and distribution activities. The revenues for transmission and distribution network's operators are assured by the payment of a use tariff. The transmission and distribution network use tariffs are established by the regulator. In Table 3 there is the peak and off peak low voltage net access tariffs imposed in Portugal in the last years.

\begin{tabular}{|c|c|c|c|c|}
\hline $\begin{array}{c}\text { Low voltage net access } \\
\text { tariffs }\end{array}$ & 2008 & 2009 & 2010 & 2011 \\
\hline Peak [cents/kWh] & 7.45 & 5.39 & 9.09 & 8.92 \\
Off peak [cents/kWh] & 3.28 & 0.68 & 3.76 & 3.86 \\
\hline
\end{tabular}

Table 3. Evolution of low voltage net access regulated tariffs in Portugal

Apart from the networks access regulated tariffs and wholesale prices, consumers should have to pay also retailing electricity costs. These activities work in competition as the established model imposed the existence of electricity wholesale and retail markets and the possibility for any customer to choose between different retailers. Depending on the retailer that each end consumer chooses, the cost of electricity to be paid by consumers should include the cost that the retailer paid for the energy at the wholesale electricity market plus the value of the regulated net access tariffs plus the revenue for the retailer. Considering a $4 \%$ on the wholesale electricity cost for the retailer revenue and the values presented in Table 3, Fig. 13 depicts the evolution of the final cost of energy that a low voltage domestic consumer should pay along the day.

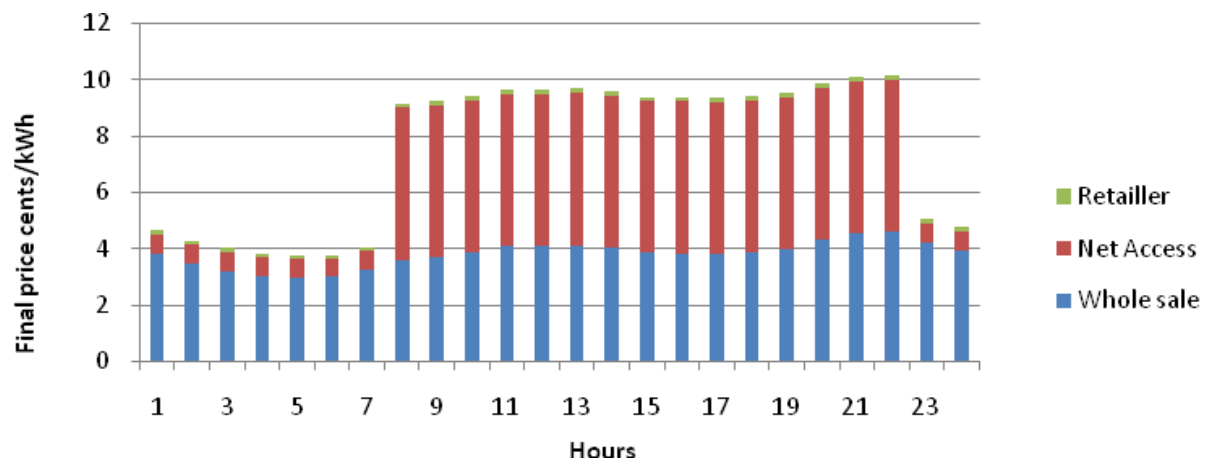

Fig. 13. Average daily evolution for final costs of energy for a domestic consumer in 2009 
This difference in costs that is reflected more or less in the regulated prices between peak and off-peak consumption should influence EVs' recharging profiles.

\section{Electric vehicle modelling}

Electric drive vehicles with the plug-in capability are only beginning to be commercially available. It would be necessary to have an idea of the capability of mass production and market penetration of these vehicles depending on their critical components development phases (namely the most critical element - the battery). The type of mobility provided by the plug in vehicles will be an important aspect because it influences vehicle's charging needs. The demand side of the transportation sector needs to be studied and it is inevitable that the consumer/passenger behavior will deeply affect future mobility. Each country's fleet profile is largely dependent on economical and political/taxation aspects, for instance, Portugal has a relatively new fleet, but it is very difficult to access the fleet's renovation rate because there are few incentives to disposal. However, these will be crucial aspects, as they will be relevant to the new vehicle technologies market penetration.

The EV's energy requirements and the expected power capacity in terms of the charging circuit and the capacity of the batteries are important requisites that define the time needed for charging and the all-electric autonomy of the vehicle.

The expected evolution of the grid capacity to support recharge at any time and the energy production technologies are important to compute EVs energy use and emissions associated. In isolated regions, such as Islands the introduction of intermittent renewable has more problems because it is not connected to a robust large Continental grid. How to benefit from using off-peak capacity and the possibility of the charging coincides with renewable energy sources?

\subsection{Energy needs}

How much power can be provided to an EV or a PHEV and during how much time?

The power demand on the grid will be a function of the voltage and current of the connection point to the grid. The capacity of the battery will then determine the length of time it will take to recharge the battery, given the connection strength. EPRI has conducted several studies on PHEV capabilities (EPRI, 2002), (Duvall, 2006) and several options are possible. Adapting to the European mainland reality, it is possible to charge the vehicles at 230 volts AC with $2,5 \mathrm{~mm}^{2}$ wire's section (16 A circuit current) that would be about $3,5 \mathrm{~kW}$ or with $4 \mathrm{~mm}^{2}$ wire's section ( $25 \mathrm{~A}$ circuit current) and that would be about $5 \mathrm{~kW}$.

It is also possible to charge fast in stations, and this at a higher power level that may go till $50 \mathrm{~kW}$. While a slow charge can last $6-8$ hours at $100 \%$ state of charge (SOC), a fast charge can last $15-30$ minutes but only allows $80 \%$ SOC and with less battery efficiency (while a slow charge can have an efficiency of $80 \%$ a fast charge's is reduced to $55 \%$ ).

The average daily energy needs to charge an EV depends on the daily mileage expected for the vehicle. The time and power of the recharge will define the EV's charging profile and the aggregation of all EVs, the extra load the electric system has to supply. A few EVs have no effect in the power grids but a mass penetration of plug-in vehicles should be simulated so that the electric utilities are prepared with the best strategies for a synergetic combination of the transportation and electricity production systems. 


\subsection{EVs market penetration}

There are many factors regarding user preference for electric vehicle technology. The most pragmatic and objective causes that may a rational potential vehicle buyer decide not to choose this technology are:

- Fuel availability (the availability of charging infrastructures)

- Range limitations for the BEV configurations

- Acquisition costs

\subsubsection{Fuel availability/charging network}

PHEVs and BEVs are designed such that they can be plugged into a home garage at night for fuelling. Garages are most frequently lacking in dense urban areas, the very places where an electric vehicle is an ideal solution for personal transportation. For example, in Lisbon only one in six cars are parked in private garages and these include apartment and condominiums with a parking place with need to plug-in (CML 2002).

In addition to the lack of garage access, the limited electricity-only range of plug-in vehicles will prompt the desire for drivers to "top off" their batteries when away from their normal overnight charging location. Electric vehicles must be plugged into the grid to refuel, but a public infrastructure to provide this service does not yet exist. Prospective plug-in car owners want the assurance that they can charge their vehicles at home, while at work, or parked anywhere for extended periods. There is a need for parking/charging points for slow charge and fast charging stations.

On average, cars are parked roughly 23 hours per day in home garages, apartments, condominiums and hotel garages, employee parking locations, public lots and curbside. To meet driver demand for convenient charging, these are the locations in which charging points should be installed.

\subsubsection{Range limitations for BEV configurations}

The limited driving range of pure EVs creates what is known as "range anxiety", which affect drivers as soon as the battery charge falls below $50 \%$. Fast charging could alleviate "range anxiety" by supplementing home slow charging with convenient on-road charging at opportunistic charging points. In one 10-minute charge cycle, fast charge technology can provide enough energy to allow an EV to operate for another $60 \mathrm{~km}$ (Szczepanek A., Botsford C., 2009). With a network of fast chargers, consumers could charge anytime, anywhere - practical infrastructure akin to the gasoline fill-up model. This fast charge capability can help to enable rapid growth of the EV market by minimizing vehicle downtime. Fleets can fast charge during opportunistic breaks to maximize productive drive. Battery manufacturers believe that they could develop a battery that could cope with fast charging although the priority is to mass produce batteries at low costs, while maintaining high quality standards, safety requirements and guaranteeing a life time of more than ten years rather than introducing batteries with super fast charging capabilities.

The successful launch of Li-Ion batteries for electronic goods such as laptops and mobile phones opened the door to further developments and it may be assumed that Li-Ion batteries will be the key technology for PHEVs and EVs in the coming decade. Regardless of the future development in the area of battery based energy storage it can be concluded that the current level of performance is now so good that the automotive industry has decided to include partly or fully electrical drivelines and traction batteries in many of their near future products. 
When fast charge with safe batteries become available with increased capacity at competitive prices, the pure BEV can cover a wide range of the transport needs, especially in urban areas, and be a strong alternative to conventional transport powered by liquid fuels.

The challenge lies in setting up a commercially viable, convenient system for end customers. The difficulty is how to change drivers' mobility behavior, so that instead of going to a gas station just before the tank is empty, drivers need to charge their cars every other time they park.

There is also a third alternative for recharging EVs, the battery swapping service. This can be done in recharging stations and the change can be done in about 10 minutes for a full charged battery. This would relieve "range anxiety" giving the customer three different modes for recharge:

- $\quad$ Slow charge (7/8 hours for $100 \%)$;

- $\quad$ Fast charge (30 minutes for $80 \%$ );

- $\quad$ Batteries change (5 minutes for $100 \%$ ).

The recharge service price should increase as time decreases. A fair price for each of these recharging models should be established, and this would both be high enough to infrastructure's investment recovery and low enough to be advantage to customer. This service should increase the cost of electricity to recharge.

\subsubsection{Acquisition costs}

Despite growing environmental awareness in society, studies have repeatedly shown that customers are only willing to pay a limited price for being "green". This means that EVs and PHEVs must be attractively priced, not only in terms of initial purchase price, but also the ongoing costs each month. The costs of EVs are still much higher than for conventional cars due to a low production volume and expensive battery packs. This reflects directly the manufacturing costs. On the other hand, the expenses per travelled $\mathrm{km}$ are quite attractive comparatively to gasoline use, for EV technological solution it is around $1 / 4$. With present prices pure electric vehicles pay off in terms of cost only if long distances are driven (higher than $200000 \mathrm{~km}$ ) (Baptista, 2009). This fact is important when calculating eventual tax incentives to purchase these kinds of technologies, having in mind that the final consumer is extremely sensitive to the " $\mathrm{km}$ for breakthrough". These limitations force Governments incentives to push the penetration of electric vehicles. There are predictions on the evolution of EVs' batteries capacity, density and price for the coming years. According to some consultancy analysis (Roland Berger, 2008) battery costs are expected to decrease to half the price from 2010 to 2020 .

\subsection{EVs recharging profiles}

There are many possibilities of vehicles charging profiles. Some could be more likely to happen but the uncertainty is high as it depends on vehicles charging requirements and drivers mobility patterns. Many studies performed included different charging scenarios.

\subsubsection{Uncontrolled charging}

Under this charging profile it is considered that each EV begins charging as soon as it is plugged in, and stops when the battery is fully charged in case of normal time charge or $80 \%$ SOC in case of fast charge. This can be considered a reference case without any intelligent control of how and when charging occurs, or incentives (such as time-of-use 
rates) to influence individual consumer behavior. The majority of charging is home charging though a little services charging is also considered. The uncontrollable charge could be as depicted in Fig. 14.

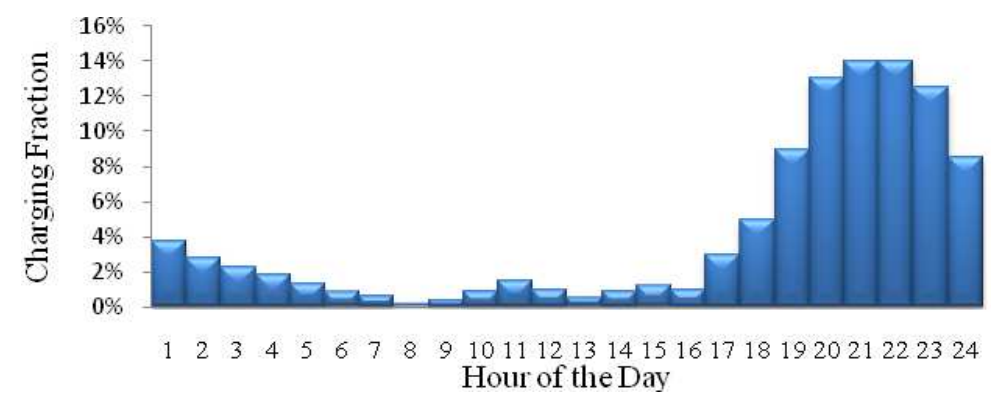

Fig. 14. Expected charging profile for uncontrolled charging scenario

\subsubsection{Off-peak charging}

This charging scenario assumes that almost all charging occurs at home in the overnight hours. Given existing incentives for off-peak energy use it attempts to better optimize the use of low cost off peak energy by delaying initiation of household charging until $10 \mathrm{pm}$ (Fig. 15) or 11pm according to the utility policy to promote off-peak demand.

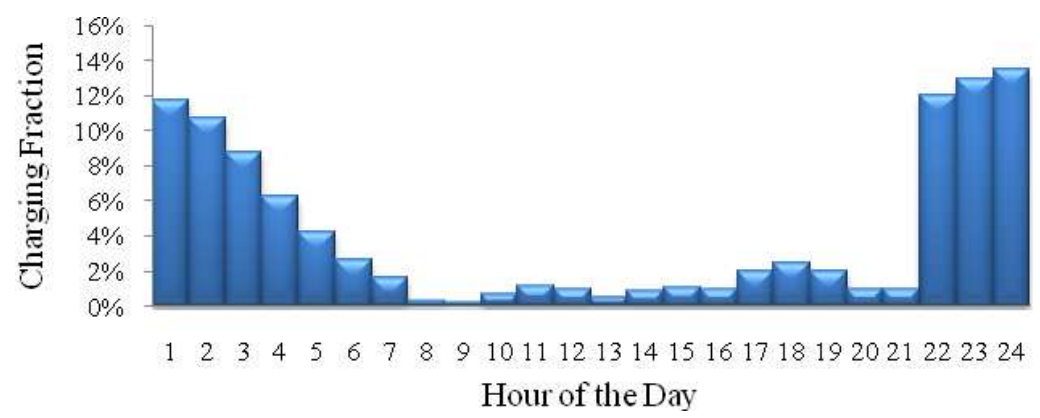

Fig. 15. Expected charging profile for off-peak charging scenario

Under this recharging profile, a peak at 10 pm should be expected in a high EV penetration scenario. This peak could be smoothed with scheduled strategies for off-peak recharge (Fig. $16)$.

\subsubsection{Optimal charging}

This charging scenario also assumes that almost all charging occurs at home during the off-peak hours, however it attempts to provide the most optimal low cost charging electricity by assuming that the vehicle charging can be controlled directly by the local utility. This allows the utility to precisely match the vehicle charging to periods of minimum demand, allowing the use of lowest cost electricity, and improving overall utility system performance. 


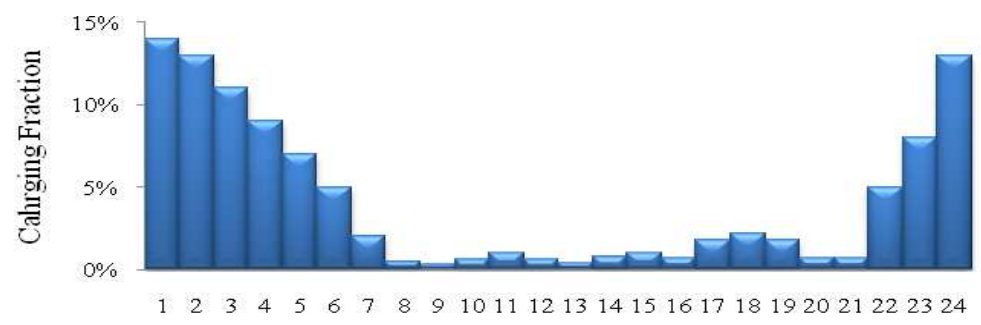

Hour of the Day

Fig. 16. Expected charging profile for a smothing off-peak charging scenario

\section{Impacts on primary energy consumption, fossil fuels use, GHG emissions and electricity costs}

The impacts of EVs and PHEVs charge on the electric utilities depend on the first place of the combination of vehicles' penetration and charging profile scenarios. The case studies considered in this chapter arise from the combination of different scenarios of electric vehicle penetration and recharging operation. For each scenario, the following variables should be analyzed:

- Primary energy needs for the electric and transportation sector working as separate systems (BAU) and working together (EVs scenarios);

- $\quad$ Effects in electricity load profiles.

- Impacts on overall energy and $\mathrm{CO}_{2}$ emissions

- Impacts on electricity costs.

- Impacts on fossil fuels use and imports.

\subsection{Primary energy consumption and fossil fuels use and GHG emissions}

Energy consumption, fossil fuels use and $\mathrm{CO}_{2}$ emissions from electricity production and transportation (the light duty fleet segment) can suffer great reductions with the integration of these two sectors by transport electrification. The replacement of a great amount of ICEVs by EVs in a country in which power generation accounts with more than $50 \%$ of renewable sources has great impacts in fossil fuels use and $\mathrm{CO}_{2}$ emissions reductions.

In terms of electricity production mix, with plenty renewable sources for generation, two extreme cases can be considered:

1. A dry year, with high prices offers for hydro and natural gas production, the supply curves per technology could have the following forms considered a certain power installed per technology (Fig. 17a).

2. A wet year, with low prices offers for hydro and also natural gas production, the supply curves per technology could have the forms depicted in Fig. $17 \mathrm{~b}$.

The expected load profiles for 2020 in a dry year hypothesis for a 2 million EVs scenario (about $1 / 3$ of LD fleet replacement) should be as depicted in Fig. 18. A peak effect in load diagram in an uncontrollable recharge profile can be observed. By transport electrification, even in the worst situation of uncontrollable recharge, a $2 \%$ decrease in primary energy use, $9 \%$ in fossil fuels use (due to great reductions in the transportation sector) and $8 \%$ in $\mathrm{CO}_{2}$ emissions can be achieved by transport electrification when compared with the case without 
EVs. An off-peak recharge profile with mass EVs penetration has more effects in energy, fossil fuels use and emissions reductions. In fact it was verified a $4 \%, 10 \%$ and $9 \%$ reduction respectively.
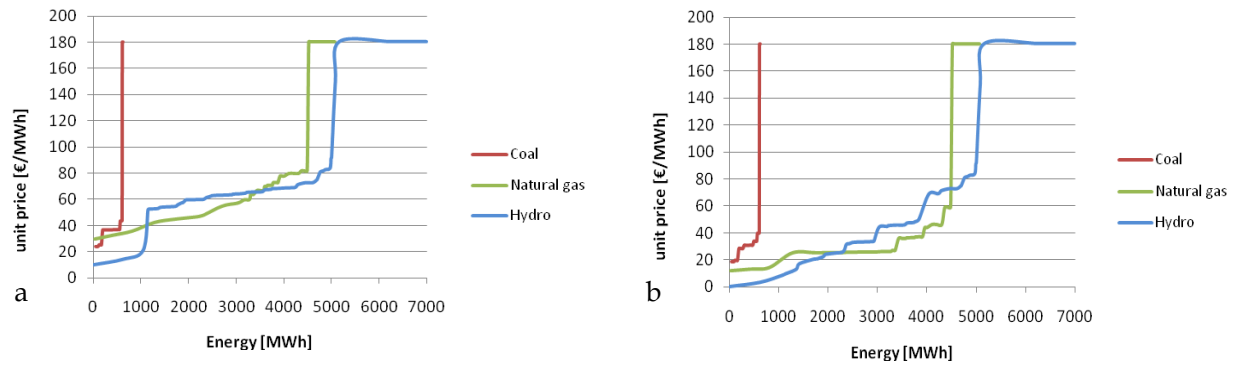

Fig. 17. Example of supply curves per technology with a) high prices for hydro and natural gas production; b) low prices for hydro and natural gas production

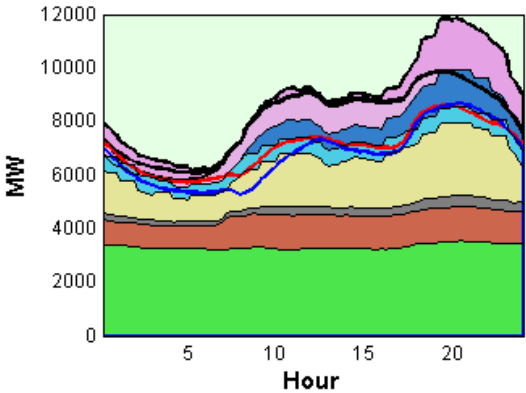

Weekdays _ $58 \%$ Renewable Saturdays _ $63 \%$ Renewable Sundays _ $69 \%$ Renewable

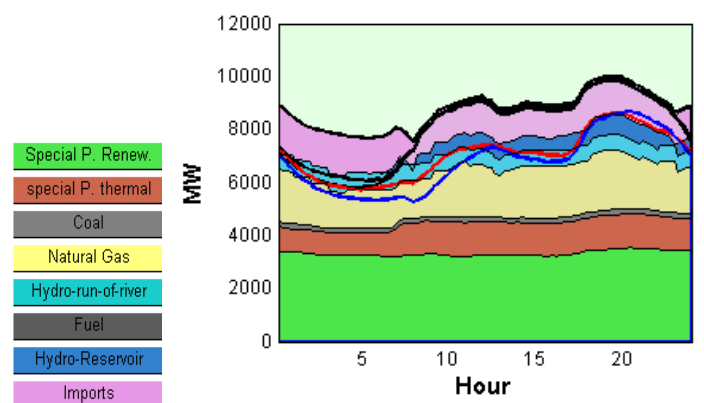

Weekdays. $58 \%$ Renewable

Saturdays $=66 \%$ Renewable Sundays _ $71 \%$ Renewable

Fig. 18. Example of the expected Winter demand profile for a dry year 2020 in an EVs' peak and off-peak recharge scenario
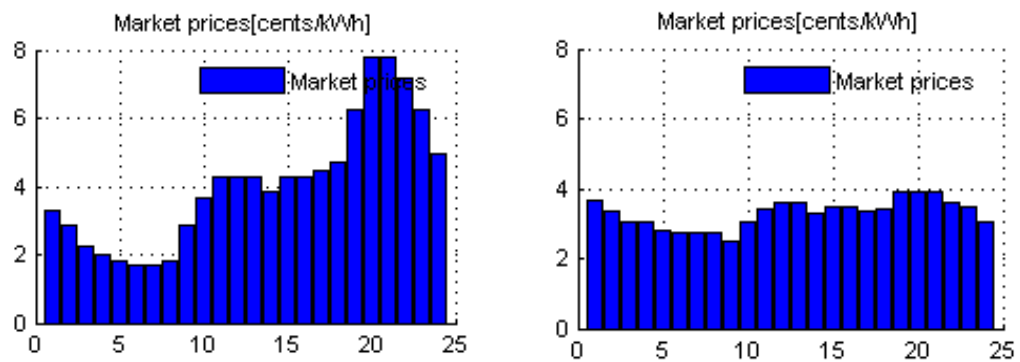

Fig. 19. Expected Winter spot prices in a peak and off-peak recharge scenarios for $2 \mathrm{M}$ EVs in Portugal mainland 
In any situation the integration of the electricity generation and transportation sectors has energy and environmental advantages. The decrease of fossil fuel use brings also economic advantages in the trading balance as all fossil fuels are imported in this example country.

In terms of the electricity wholesale prices, in a high EV penetration scenario, the leveling of the spot prices follow the leveling of the load profile (Fig. 19).

It is expectable that the peak effect of uncontrollable charging would cause price sparks at the peak hours. A time of use price for EVs recharge must be done to avoid this situation.

In the Island example as stated in sections 2.2 and 2.3.1, uncontrollable EVs recharge has worse consequences in renewable penetration and production prices.

\subsection{Electricity costs, the fuel costs for EVs}

As stated in section 2.3., electricity costs for EVs' recharge, either in a market context or as a vertically owned company is a sum of different costs related to production, net use and retailing of the product to the final client. To illustrate the differences, we have two case studies, the mainland, where there is competition in the production and retailing markets and S. Miguel Island where the same company monopolises all activities.

Adding all the costs associated to electricity supply service, for the mainland case, in a scenario of low hydro production the price could reach 17 cents/kWh, for 2 Million EVs charging mainly at peak hours, this includes the whole sale price $(8 \mathrm{c} € / \mathrm{kWh})$ plus the net access tariff (the 2010 regulated tariff was used in this example, $9.09 \mathrm{c} € / \mathrm{kWh}$ ) plus the retailer revenue (a $4 \%$ of the wholesale, $0.32 \mathrm{c} € / \mathrm{kWh}$ ). In a high hydro production and low wholesale prices, an off peak recharge could reach the 5.6 cents $/ \mathrm{kWh}$. In these extreme conditions EV energy prices could be between $0.9 €$ to $2.8 €$ per $100 \mathrm{~km}$. Compared with the most efficient ICEV cars and the present gasoline and Diesel prices in Portugal that can spend between $4.5 €$ and $8.2 €$ per $100 \mathrm{~km}$, there are great advantages in charging EVs during off-peak hours. These simulations were made considering for the vehicles a slow recharge at low voltage at home or at service and no extra charge is considered to pay for the parking/charging service.

For the Island case study, an uncontrollable recharge must be forbidden, as the final electricity costs would reach the 20 cents/ $\mathrm{kWh}$, with all the environmental consequences as EVs would be recharged mainly with fuel oil. An off-peak recharge could cost only 8 cents/kWh, considered the regulated tariffs imposed (ERSE, 2011). In the Island EVs energy costs can be between $1.3 €$ and $3 €$ per $100 \mathrm{~km}$.

\section{Conclusion}

Electric vehicles (EVs) and plug-in hybrid electric vehicles (PHEVs), which obtain their fuel from the grid by charging a battery, are set to be introduced into the mass market and expected to contribute to oil consumption reduction. PHEVs and EVs can also provide a good opportunity to reduce $\mathrm{CO}_{2}$ emissions from transport activities if the electricity they use to charge their batteries is generated through low carbon technologies. In addition to the environmental issue, EVs bring techno-economical challenges for utilities as well, because EVs will have great load flexibility as they are parked $93 \%$ of their lifetime, making it easy for them to charge either at home, at work, or at parking facilities, hence implying that the time of day in which they charge, can easily vary. 
The replacement of a great amount of ICEVs by EVs in a country in which power generation accounts with more than $50 \%$ of renewable sources has great impacts in fossil fuels use and $\mathrm{CO}_{2}$ emissions. The results obtained from the simulations show that, a mass penetration of electric vehicles in Portugal, contributes to decrease energy consumption, fossil fuels' use (mainly oil) and $\mathrm{CO}_{2}$ emissions from the two sectors (electricity production and transportation) that nowadays most contribute to the emissions from fossil fuels burning.

The pressure to generate electricity from endogenous low carbon resources in the majority of the countries makes naturally transport electrification a solution to lower emissions and fossil energy use from the transportation sector also. The cost and range of the vehicle remain the main bottlenecks for EVs penetration.

The cost of the energy to charge the EV is highly dependent on the electricity generation technologies in the first place, the electricity market structure (whether there is concurrence or not) and the time of recharge (peak or valley recharge) makes the rest influence on final costs.

In the examples used in this chapter, scenarios of EV penetration (energy needed) and recharge profile (hourly power demand) combined with the extreme cases of expected electricity production lead to different wholesale prices and hourly price profile, as well as fossil fuels use and emissions associated to charge the EVs, leading to different costs of the EV fuel per $\mathrm{km}$.

Facing the increasing oil prices, the cost of energy per $\mathrm{km}$ of the EVs became even more advantageous when compared to ICEVs fuel costs and enough to overcome the initial purchase costs difference.

\section{Acknowledgment}

Thanks are due to the MIT Portugal Program and Fundação para a Ciência e Tecnologia for the PhD financial support (SFRH/BD/35191/2007) POS_Conhecimento. The authors would like to acknowledge FCT- Fundação para a Ciência e Tecnologia through the national project MMSAFU - Microssimulation Model to Simulate Alternative Fuel Usage (POCI/ENR/57450/2004), and national project Power demand estimation and power system impacts resulting of fleet penetration of electric/plug-in vehicles (MIT-Pt/SESGI/0008/2008).

\section{References}

Baptista, P., Camus, C., Silva, C., Farias, T. (2009) Impact Of The Introduction Of Electric Based Vehicles In São Miguel Island, 10th Conference on Energy for a Clean Environment, July 2009

CML Lisbon City Hall, Lisbon (2002): The mobility challenge, 2002, available at http://ulisses.cm-lisboa.pt/data/002/002/pdf/mobilidade.pdf (last accessed 09/05/25)

Denholm, P. and Short, W. (2006), An Evaluation of Utility System Impacts and Benefits of Optimally Dispatched Plug-In Hybrid Electric Vehicles, Technical Report NREL/TP620-40293, October 2006. 
Duvall, Dr. Mark S. (2006), "Plug-in hybrid electric Vehicles Technology Challenges", EPRI Sep 2006

EDA - Electricity of Azores, available at www.eda.pt

EPRI (2006), Comparing the Benefits and Impacts of Hybrid Electric Vehicle Options for compact sedan and sport utility vehicles, EPRI,1006892. July 2002

ERSE (2011), http://www.erse.pt/pt/electricidade/tarifaseprecos/Paginas/default.aspx. (last accessed 11/01/15)

Hadley, Stanton W. (2006), Impact of Plug-in Hybrid Vehicles on the Electric Grid, October 2006

Hadley, Stanton W. (2008), Potential Impacts of Plug-in Hybrid Vehicles on Regional Power Generation, ORNL/TM-2008/150, January 2008.

IEA (2007) International energy agency - World Energy Outlook 2007, (pp. 93 assessed at $09 / 05 / 19$ ) at http://www.iea.org/textbase/nppdf/free/2007/ weo_2007.pdf

IEA (2008) International energy agency - World Energy Outlook 2008. (pp. 508 assessed at 10/10/19) available online at $h$ ttp://www.iea.org/Textbase/about/copyright.asp

IEA (2008), Energy Tecnology Perpectives 2008, Chapter 15 Transport

IPCC (2007), “Fourth Assessment Report. Climate Change 2007: Synthesis Report. Summary for Policy Makers", 2007.

EVWorld (2009), http:/ / www.evworld.com/index.cfm (last assessed at 20/05/09)

EVreportlinker (2009), http://www.reportlinker.com/p059605/Electric-Vehicles.html (last assessed 20/05/09)

Kempton,W., Tomic,J., (2005a) Vehicle-to-grid power fundamentals: calculating capacity and net revenue, J. Power Sources 1442005 268-279.

Kempton, W., Tomic, J.,(2005b) Vehicle-to-grid power implementations: from stabilizing the grid to supporting large-scale renewable energy, J. Power Sources 1442005 280-294.

Kintner-Meyer Michael, Kevin Schneider, Robert Pratt, (2007) Impacts assessment of plug-in hybrid vehicles on electric utilities and regional u.s. power grids", Part 1: technical analysis, Pacific Northwest National Laboratory (a), November, 2007.

OMEL (2009) Electricity Market Operator, available at www.omel.es, assessed at $09 / 10 / 10$

Parks, K., Denholm, P., Markel,T. (2007), Costs and Emissions Associated with Plug-in Hybrid Electric Vehicle Charging in the Xcel Energy Colorado Service Territory, Technical Report NREL/TP-640-41410, May 2007

Roland Berger Strategy Consultants (2008), “Value for EDP in Electric Vehicles, Lisbon, July 29th , 2008

Scott, Michael J., Kintner-Meyer, Michael, Elliott, Douglas B., Warwick, William M. (2007), Impacts assessment of plug-in hybrid vehicles on electric utilities and regional u.s. power grids: part 2: economic assessment. Pacific Northwest National Laboratory (a), November, 2007.

Skea, J.; Anderson, D.; Green, T.; Gross, R.; Heptonstall, P.; Leach, M., (2008) "Intermittent renewable generation and maintaining power system reliability", Generation, Transmission \& Distribution, IET Volume 2, Issue 1, January 2008 Page(s):82 - 89 
Szczepanek A., Botsford C., (2009), Electric Vehicle Infrastructure Development: An Enabler for Electric Vehicle Adoption, EVS24,Stavanger, Norway, May 13-16, 2009 


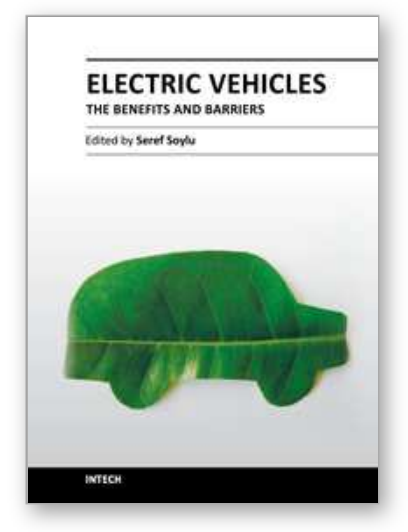

\author{
Electric Vehicles â€“" The Benefits and Barriers \\ Edited by Dr. Seref Soylu
}

ISBN 978-953-307-287-6

Hard cover, 240 pages

Publisher InTech

Published online 06, September, 2011

Published in print edition September, 2011

In this book, theoretical basis and design guidelines for electric vehicles have been emphasized chapter by chapter with valuable contribution of many researchers who work on both technical and regulatory sides of the field. Multidisciplinary research results from electrical engineering, chemical engineering and mechanical engineering were examined and merged together to make this book a guide for industry, academia and policy maker.

\title{
How to reference
}

In order to correctly reference this scholarly work, feel free to copy and paste the following:

Cristina Camus, Jorge Esteves and Tiago Farias (2011). Integration of Electric Vehicles in the Electric Utility Systems, Electric Vehicles â€" The Benefits and Barriers, Dr. Seref Soylu (Ed.), ISBN: 978-953-307-287-6, InTech, Available from: http://www.intechopen.com/books/electric-vehicles-the-benefits-andbarriers/integration-of-electric-vehicles-in-the-electric-utility-systems

\section{INTECH}

open science | open minds

\section{InTech Europe}

University Campus STeP Ri

Slavka Krautzeka 83/A

51000 Rijeka, Croatia

Phone: +385 (51) 770447

Fax: +385 (51) 686166

www.intechopen.com

\section{InTech China}

Unit 405, Office Block, Hotel Equatorial Shanghai

No.65, Yan An Road (West), Shanghai, 200040, China

中国上海市延安西路65号上海国际贵都大饭店办公楼 405 单元

Phone: +86-21-62489820

Fax: $+86-21-62489821$ 
(C) 2011 The Author(s). Licensee IntechOpen. This chapter is distributed under the terms of the Creative Commons Attribution-NonCommercialShareAlike-3.0 License, which permits use, distribution and reproduction for non-commercial purposes, provided the original is properly cited and derivative works building on this content are distributed under the same license. 